\title{
Epidemiology of human visceral leishmaniasis in the urban centers of the lower-middle São Francisco Valley, Brazilian semiarid region
}

\author{
Lucyo Flávio Bezerra Diniz ${ }^{[1]}$, Carlos Dornels Freire de Souza ${ }^{[2]}$ \\ and Rodrigo Feliciano do Carmo ${ }^{[1],[3]}$
}

\author{
[1]. Programa de Pós-Graduação em Ciências da Saúde e Biológicas, Universidade Federal do Vale do São Francisco, Petrolina, PE, Brasil \\ [2]. Faculdade de Medicina, Universidade Federal de Alagoas, Arapiraca, AL, Brasil. \\ [3]. Colegiado de Ciências Farmacêuticas, Universidade Federal do Vale do São Francisco, Petrolina, PE, Brasil
}

\begin{abstract}
Introduction: Visceral leishmaniasis (VL) is a zoonosis caused by parasites of the Leishmania genus. VL is present in countries with tropical climates, being endemic in Brazil,, including the region of the lower-middle São Francisco Valley which includes the urban centers of Petrolina (Pernambuco state) and Juazeiro (Bahia state). Methods: This retrospective and descriptive epidemiological study analyzed secondary data obtained from the mandatory visceral leishmaniasis notification forms of the Ministry of Health, which were compiled in the Information System for Notifiable Diseases (SINAN) database. We analyzed 181 autochthonous cases reported in the two aforementioned cities between 2010 and 2016. Data collection occurred in June 2017. Results: Of the 181 VL cases in the study area, 40.9\% ( $\mathrm{n}=74)$ occurred in Juazeiro and 59.1\% $(\mathrm{n}=107)$ occurred in Petrolina. The average numbers of cases per year were 9.5 in Juazeiro and 14 in Petrolina; respectively, the incidence ranges were 2-8.6 cases and 2.8-6.1 cases per 100,000 inhabitants. Fever, weakness, weight loss, and pallor were the most commonly observed clinical manifestations. Coinfection with human immunodeficiency virus (HIV) was observed in $16.8 \%$ and $5.4 \%$ of cases in Petrolina and Juazeiro, respectively. The lethality rates were $2.8 \%$ and $5.4 \%$ in Petrolina and Juazeiro, respectively. Conclusions: Both cities had a high incidence of VL during the studied period. The findings of this study contribute to a better understanding of the behavior of VL during recent years and may help to direct regional disease control measures.
\end{abstract}

Keywords: Kala-azar. Epidemiology. Visceral leishmaniasis.

\section{INTRODUCTION}

Visceral leishmaniasis (VL) is a zoonosis caused by obligate intracellular parasites of the Leishmania genus. Particularly, this systemic clinical spectrum involves the species Leishmania donovani, which is restricted to Africa and the Indian subcontinent, and Leishmania infantum, to Europe and the Americas. VL is transmitted to humans by several species of Phlebotominae, particularly Lutzomyia Longipalpis. The disease progression is serious and can be fatal if left untreated ${ }^{1}$.

According to the World Health Organization, VL is endemic to 98 countries; however, $90 \%$ of cases are concentrated in Bangladesh, Nepal, Sudan, India, and Brazil'2. In Brazil, VL has undergone an urbanization process over the past 30 years, and is now endemic and epidemic in large cities within the nation's

Corresponding author: Dr. Rodrigo Feliciano do Carmo. e-mail: rodrigo.carmo@univasf.edu.br

Received 26 February 2018

Accepted 5 July 2018 macroregions; several states in the Northeast are principally affected, including Pernambuco and Bahia ${ }^{2,3}$. Since the 1990s, changes in the epidemiological profile of the disease have occurred in all of the mesoregions of these states, and an evident geographical expansion of the disease occurred in the interior of Pernambuco between 1990 and 2001',5.

The macroregion of the lower-middle São Francisco Valley, which encompasses the Pernambuco-Bahia (PEBA) Integrated Attention Network comprising the principal municipalities of Petrolina (Pernambuco state) and Juazeiro (Bahia state), forms a hyperendemic belt with incidence rates as high as 10 cases per 100,000 inhabitants ${ }^{6}$.

Given the high endemicity of VL in this region, this study aimed to determine the epidemiological aspects of the disease in the Cities of Petrolina and Juazeiro between 2010 and 2016 and to compare the epidemiological profiles of these two cities.

\section{METHODS}

This retrospective, descriptive, and epidemiological study analyzed secondary data obtained from the mandatory visceral leishmaniasis notification forms of the Ministry of Health, 
which were compiled in the Information System for Notifiable Diseases (SINAN) database.

As noted above, the municipalities of Petrolina and Juazeiro are the principal urban centers of the PEBA Network. The PEBA region comprises 52 municipalities in the semiarid Northeast region, and ranges from the basin of the lower-middle São Francisco Valley in Northern Bahia to the Western edge of Pernambuco. In the lower-middle zone of the São Francisco River, the City of Juazeiro is located on the right-hand bank of the São Francisco River in the far North of Bahia, and had an estimated population of 220,253 inhabitants as of 2016. This municipality borders the State of Pernambuco and is connected to Petrolina by the Presidente Dutra Bridge. Juazeiro is located approximately $500 \mathrm{~km}$ from Salvador, Bahia. Petrolina is located in the sertão region of Pernambuco, in the VIII Regional Health District of the state. The estimated population of Petrolina was 337,683 inhabitants as of $2016^{7}$.

The study population comprised all autochthonous cases reported between 2010 and 2016 in the urban centers of the lower-middle São Francisco Valley, namely Petrolina and Juazeiro. Autochthonous cases were defined as those where the place of infection and municipality of residence were the same ${ }^{6}$. Data collection took place in June 2017.

Graphs and tables were generated using Excel ${ }^{\circledR}$ version 2016 (Microsoft Corp., Redmond, WA, USA). Data are presented as relative and absolute frequencies. Frequencies were compared using the chi-squared test or Fisher's exact test when appropriate. Differences were considered statistically significant at a $p$ value $<0.05$. The statistical analysis was performed using GraphPad Prism software, version 6.01 (GraphPad Software Inc., San Diego, CA, USA).

A segmented regression model (joinpoint) was applied for the trend analysis. This type of model tests whether a multi-segmented line better explains the temporal behavior of a particular event when compared with a straight or less segmented line ${ }^{8}$.

The model was used to identify trends in the indicator (stationary, increasing, or decreasing), points of change in this trend (inflections), and the annual percentage change (APC) and average annual percentage change (AAPC). The confidence interval $(95 \% \mathrm{CI})$ was calculated for each detected trend. A significance level of $5 \%$ was adopted. Joinpoint software, version 4.5.0.1 (Statistical Research and Applications Branch, National Cancer Institute, Rockville, MD, USA) was used for this analysis.

\section{Ethical considerations}

This study was approved by the Committee of Ethics and Deontology in Study and Research of the Federal University of São Francisco Valley. The protocol is catalogued under the following CAAE protocol number: 68562617.3.0000.5196.

\section{RESULTS}

Between 2010 and 2016, 181 cases of VL were confirmed in the municipalities of Juazeiro and Petrolina, which respectively accounted for $40.9 \%(n=74)$ and $59.1 \%(n=107)$. The average numbers of cases per year during the studied period were 9.5 in Juazeiro and 14 in Petrolina.

Our analysis of the incidence rates of the two municipalities revealed variations of 2-8.6 cases per 100,000 inhabitants in Juazeiro and of 2.8-6.1 cases per 100,000 inhabitants in Petrolina. The highest incidence rate in Juazeiro was observed in the year 2010 (8.6 cases per 100,000 inhabitants). In Petrolina, the highest incidence rate was observed in the year 2014 (6.1 cases per 100,000 inhabitants). The lowest incidence years were 2012 for Juazeiro ( 2.0 cases per 100,000 inhabitants) and 2013 for Petrolina (2.8 cases per 100,000 inhabitants) (Figure 1).

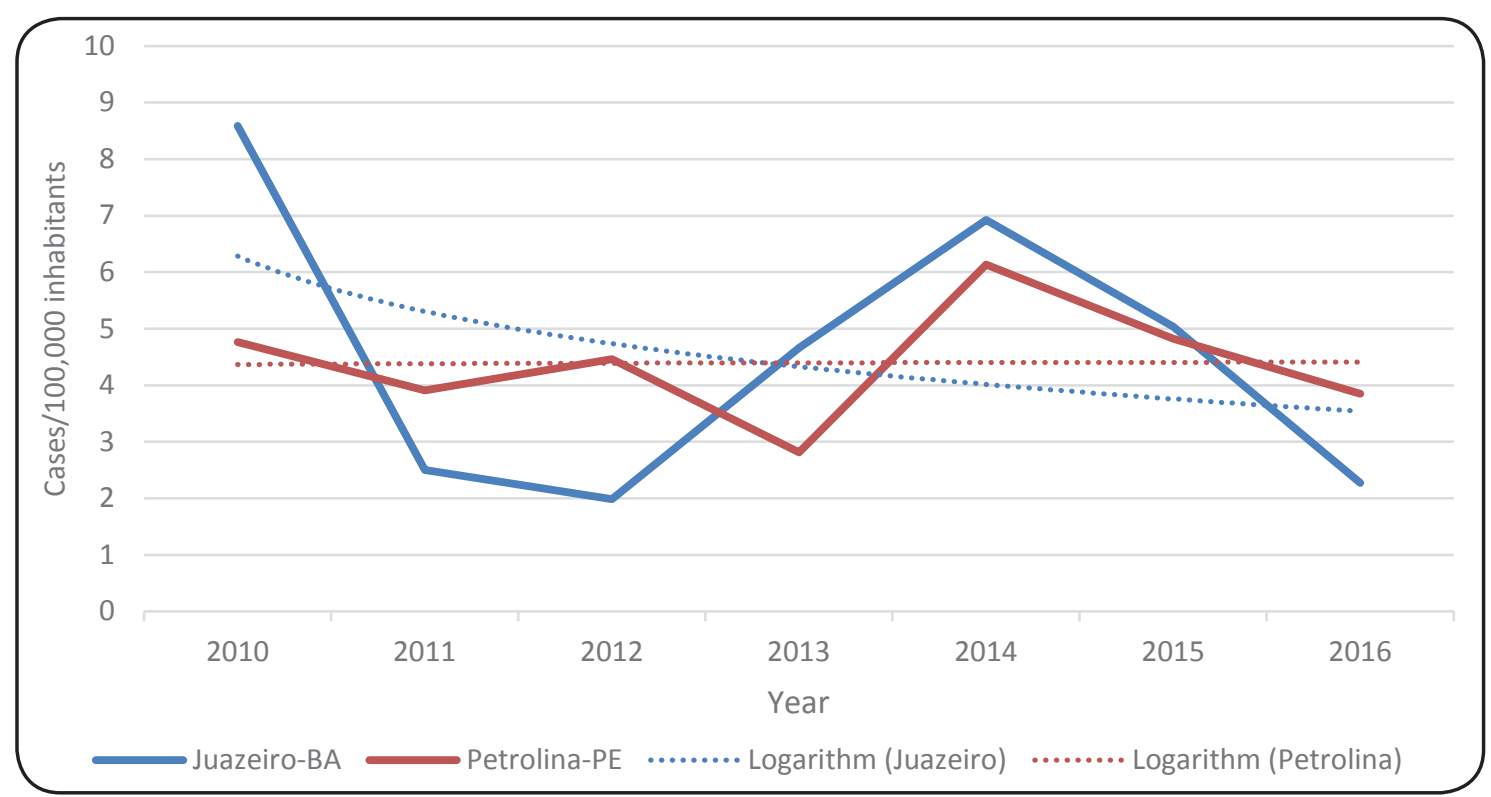

FIGURE 1: Incidence of human visceral leishmaniasis in the municipalities of Petrolina and Juazeiro between the years of 2010 and 2016. 
Using the segmented regression model, we observed that the incidence rates in both Juazeiro and Petrolina exhibited stationary behavior ( $p=0.7$ and 0.9 , respectively). The model did not demonstrate the existence of inflection points ( $p=0.6$ and 0.8 ), possibly due to the length of the time series and instability of the data. An annual percentage change of $-4.7 \%$ [95\% confidence interval $(95 \% \mathrm{CI}):-29.5$ to 28.9 ] was highlighted in Juazeiro, whereas an APC of $0.4 \%$ (95\% CI: -11.8 to 14.2$)$ was calculated for Petrolina.

Table 1 compares the sociodemographic characteristics of VL cases in the two studied municipalities. Similar characteristics were observed between the two municipalities; notably, the populations were predominantly male, young $(<15$ years old), pardo (multiracial), rural, and had low levels of education. The frequency of cases in urban areas was slightly higher in Petrolina than in Juazeiro (31.8\% and $18.9 \%$, respectively; $p=0.04$ ).

Regarding signs and symptoms, we observed that fever, weakness, weight loss, and pallor were present in $>50 \%$ of diagnosed cases. The frequency of cases with hemorrhage was significantly higher in Juazeiro than in Petrolina $(p=0.01)$ (Table 2).

We observed a higher frequency of VL/HIV coinfection, in the municipality of Petrolina than in Juazeiro (16.8\% and 5.4\%, respectively). In both municipalities, a noteworthy proportion of patients either did not know their HIV status or left the response space blank, although this occurred significantly more frequently in Juazeiro $(p=0.003)$ (Table 3).

Table 4 presents the indicators of outcomes among diagnosed VL cases in the studied municipalities. The abandonment and mortality rates were slightly higher in Juazeiro than in Petrolina. Epidemiological outcomes were not reported for $14.1 \%$ of cases in Petrolina and $8.1 \%$ of cases in Juazeiro.

\section{DISCUSSION}

This study aimed to evaluate the epidemiological profile of $\mathrm{VL}$ in a hyperendemic region comprising the municipalities

TABLE 1: Sociodemographic characteristics of patients with visceral leishmaniasis in the municipalities of Petrolina and Juazeiro between 2010 and 2016.

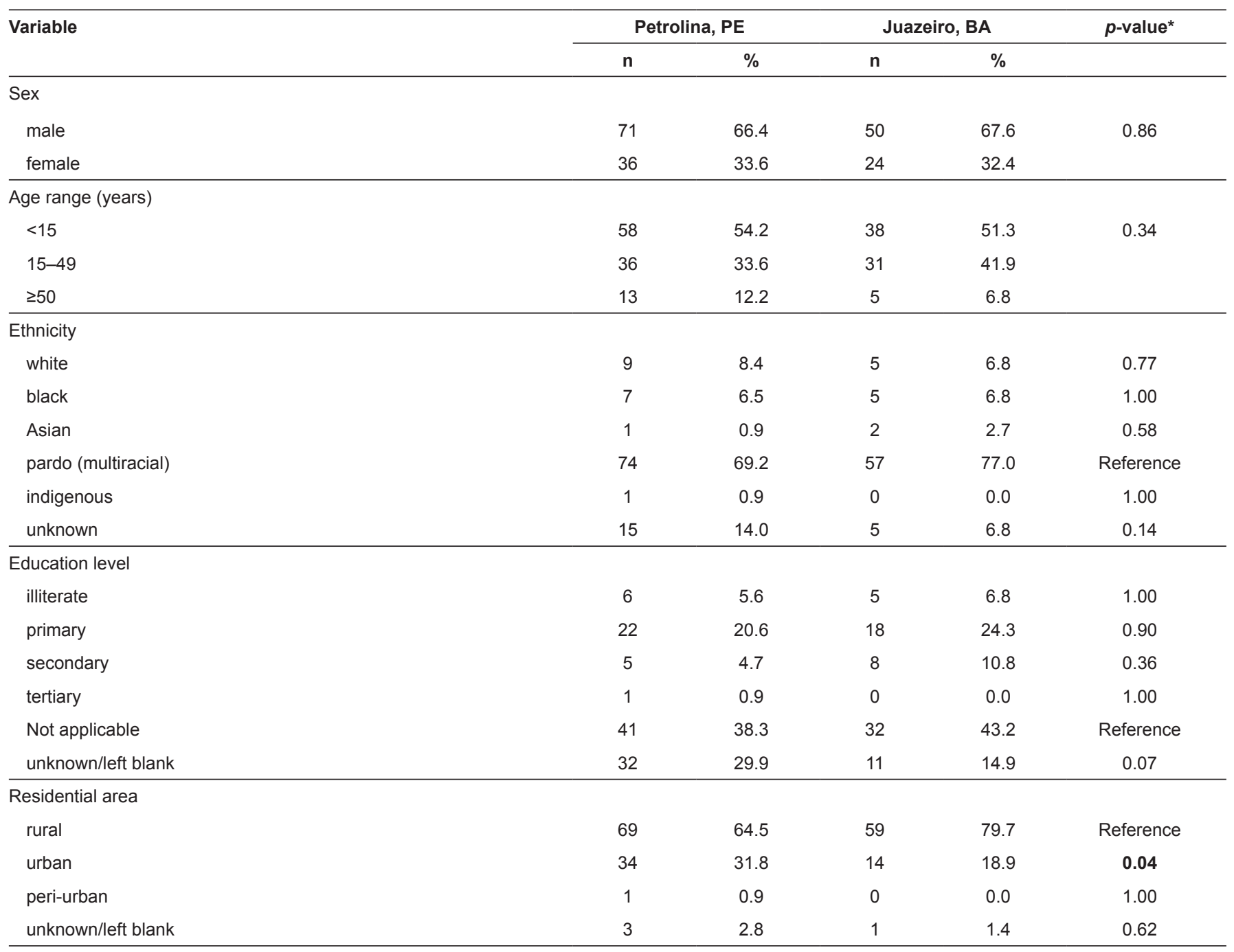

*Significant $p$-values are in bold. 
TABLE 2: Frequency of signs/symptoms in patients with visceral leishmaniasis diagnosed in the municipalities of Petrolina and Juazeiro between 2010 and 2016.

\begin{tabular}{|c|c|c|c|c|c|}
\hline \multirow[t]{2}{*}{ Variable } & \multicolumn{2}{|c|}{ Petrolina, PE } & \multicolumn{2}{|c|}{ Juazeiro, BA } & \multirow[t]{2}{*}{$p$-value* } \\
\hline & $\mathrm{n}$ & $\%$ & $\mathbf{n}$ & $\%$ & \\
\hline Fever & 94 & 87.9 & 69 & 93.2 & Reference \\
\hline Edema & 34 & 31.8 & 28 & 37.8 & 0.70 \\
\hline Weight loss & 69 & 64.5 & 51 & 68.9 & 0.97 \\
\hline Hemorrhage & 6 & 5.6 & 16 & 21.6 & 0.01 \\
\hline Jaundice & 21 & 19.6 & 26 & 35.1 & 0.11 \\
\hline Affected spleen & 67 & 62.6 & 56 & 75.7 & 0.58 \\
\hline Hepatic dysfunction & 65 & 60.7 & 48 & 64.9 & 0.98 \\
\hline
\end{tabular}

*Significant $p$-values are in bold.

TABLE 3: Visceral leishmaniasis/HIV coinfection in the municipalities of Petrolina and Juazeiro.

\begin{tabular}{|c|c|c|c|c|c|}
\hline \multirow[t]{2}{*}{ Variable } & \multicolumn{2}{|c|}{ Petrolina, PE } & \multicolumn{2}{|c|}{ Juazeiro, BA } & \multirow[t]{2}{*}{$p$-value* } \\
\hline & $n$ & $\%$ & $n$ & $\%$ & \\
\hline \multicolumn{6}{|l|}{ VL/HIV coinfection } \\
\hline no & 56 & 52.3 & 30 & 40.5 & 0.19 \\
\hline unknown/left blank & 33 & 30.8 & 40 & 54.1 & 0.003 \\
\hline
\end{tabular}

VL/HIV: visceral leishmaniasis/human immunodeficiency virus. *Significant $p$-values are in bold.

TABLE 4: Indicators of visceral leishmaniasis outcomes in the municipalities of Petrolina and Juazeiro.

\begin{tabular}{lcc}
\hline Variable & Petrolina, PE (\%) & Juazeiro, BA (\%) \\
\hline Recovery rate & 82.2 & 83.8 \\
Abandonment rate & 0.9 & 2.7 \\
Mortality rate & 2.8 & 5.4 \\
\hline
\end{tabular}

of Petrolina and Juazeiro in the lower-middle São Francisco Valley. This region has recently experienced a rapid population growth due to an intense migratory flow from other regions in Brazil, which has been attributed to industrialization and a local agriculture boom. Both municipalities are classified as intense areas of VL transmission, as both maintained an annual average of $>4.4$ cases during the past 5 years $^{6}$. During the studied period, the municipality of Petrolina had an average of 14 cases per year, greater than the number reported by Araújo et al. ${ }^{9}$ in this municipality between 2007 and $2013^{9}$.

Regarding the disease incidence, the highest rates were observed in the year 2010 in Juazeiro (8.6 cases per 100,000 inhabitants) and in 2014 in Petrolina (6.1 cases per 100,000 inhabitants). These values are higher than both the national average
(1.7 cases per 100,000 inhabitants) and the Northeast regional average (3.0 cases per 100,000 inhabitants) during the studied years ${ }^{10}$. In comparison, the City of São Luis, Maranhão (Northeast Brazil) reported the highest incidence of 5.9 cases per 100,000 inhabitants in $2005^{11}$. In Belo Horizonte, Minas Gerais (Southeast Brazil), an incidence of 5.9 cases per 100,000 inhabitants was reported in $2004^{12}$. In a study conducted in Ceará between 2007 and 2011, the City of Sobral had the highest average incidence, with 13.2 cases per 100,000 inhabitants, whereas the metropolitan area of Fortaleza had 7.8 cases per 100,000 inhabitants ${ }^{13}$. Therefore, the municipalities of Petrolina and Juazeiro had VL incidences similar to or greater than those reported in other Brazilian cities.

As VL has historically been more present in rural areas ${ }^{2}$, one may imagine that the coefficient of incidence would be higher in an area where a significant part of the population resides in rural areas. This might at least partly explain the greater incidence of VL in Petrolina than in Juazeiro ${ }^{7}$. In addition, the studied cities experienced marked migration motivated by irrigated fruit cultivation in recent decades. This movement has disrupted population growth in rural and peri-urban areas lacking health infrastructure, thus exposing residents to clusters of misery that may be related to the higher incidence of VL.

The stationary behavior of the VL incidence in both studied municipalities, as indicated by the segmented regression model, 
indicates that the VL situation did not change during the analyzed period. Likewise, a recent study of secondary data from all Brazilian states observed a near-constant number of new cases between 2009 and $2013^{14}$. The lack of public policies targeting VL, a lack of commitment from public authorities, persistence of the transmission chain, lack of transversal policies affecting the determinants of illness (e.g., income, sanitation, housing, education) and even the migratory process may have contributed to the stable number of cases throughout the studied period.

We further observed that the incidence of VL was twice as high in males than in females in both municipalities and was higher among people younger than 15 years and residents of rural areas. These data are similar to those reported by Araújo et al. ${ }^{9}$, who analyzed data from Petrolina between 2007 and $2013^{9}$. The increased susceptibility among those younger than 15 years can be explained by immunological immaturity ${ }^{15,16}$, which is aggravated by the malnutrition usually present in endemic areas and by increased exposure to the vector in peri-domestic areas ${ }^{6}$.

In endemic areas, clinical syndromes comprising constitutional symptoms (e.g., fever, weight loss and asthenia) associated with splenomegaly are important signs contributing to a VL diagnosis ${ }^{15}$. Herein, the main signs and symptoms were fever and asthenia, which were present in $90 \%$ and $66.8 \%$ of patients, respectively, consistent with data from the existing literature ${ }^{17-23}$. Weight loss and splenomegaly were also common and were observed in $65.2 \%$ and $64 \%$ of patients, respectively. Similarly, previous studies reported frequencies of splenomegaly ranging from $65.4 \%$ to $85.9 \%{ }^{17-23}$. Moreover, a higher frequency of cases with hemorrhage were reported in Juazeiro than in Petrolina, and this finding was likely associated with delayed diagnosis.

HIV coinfection was observed in $12.1 \%$ of the analyzed patients. This rate is similar to that reported by Araujo et al. in the same region; specifically, an incidence of $14.5 \%$ was reported in Petrolina during the period between 2007 and 2013. A recent report stated that the national prevalence of VL-HIV coinfection in Brazil was approximately $7 \%{ }^{14}$. We emphasize, however, that the underreporting of cases leads to an underestimation of coinfection, as indicated by the finding that the field referring to HIV infection was left blank in many of the analyzed reports. Notification failures were also observed by Souza et $\mathrm{al}^{24}$.

The clinical presentation of VL in the presence of HIV infection may be atypical; for example, the classical triad (fever, constitutional symptoms and splenomegaly), as well as jaundice and edema, is less frequently observed ${ }^{25}$. Accordingly, the diagnosis of VL is more difficult in individuals with HIV. The correlation of LV with HIV is not only relevant because coinfection indicates a worse prognosis ${ }^{26}$, but also because the hyperendemic nature of this region increases the risk of disease reactivation and the maintenance of asymptomatic hosts. Studies that aim to determine the incidence of coinfection in asymptomatic patients are needed to more accurately calculate the number of cases in the region.

If not treated promptly, VL has a high mortality rate, with estimates varying between 80 and $100 \%$. Even with treatment, however, the fatality rates exceed $10 \%{ }^{14,27}$. Mortality was observed in $5.4 \%$ of cases in Juazeiro and $2.8 \%$ in Petrolina.
More recent data from SINAN database demonstrate that the overall mortality rate of VL in Brazil varied between 3.2\% and $8.5 \%$ between the years 2010 and 2016; during this period, mortality rates ranged from $3.5 \%$ to $14.3 \%$ and from $3.5 \%$ to $11.4 \%$ in the States of Bahia and Pernambuco, respectively ${ }^{10}$. The overall lethality, therefore, was lower in the studied municipalities than in municipalities with historically high incidence rates. In 2017, Brandão et al. reported a mortality rate of $3.72 \%$ in individuals aged $\leq 19$ years in Brazil ${ }^{14}$.

The lower mortality rate observed in the present study can be partly explained by the structure of the healthcare network. The integrated network between Pernambuco and Bahia, the aforementioned PEBA Network, includes an expanded primary care and integrated referral service. This structure organized the local health system according attention levels and well-defined priorities, thus allowing the more rapid access of patients diagnosed with severe VL to hospital services.

VL is a disease of compulsory notification, and therefore all cases are potentially reported; however, the study was limited by the retrospective design and secondary data analysis. Other limiting factors include the chronic issues of underreporting, completeness, and accuracy. Despite these limitations, however, the present study was able to demonstrate the magnitude of the problem of LV in the analyzed region.

From the obtained results, the region of São Francisco, represented by the cities of Juazeiro and Petrolina, is clearly among the demographic niches with the highest incidence rates of VL in Brazil.

The present study therefore contributes to a better understanding of the behavior of LV in recent years and may help to direct regional measures to prevent and control this disease.

\section{Conflict of interest}

The authors declare that there are no conflicts of interest.

\section{Acknowledgements}

We would like to thank the Municipal Secretaries of Health in Petrolina, and Juazeiro.

\section{REFERENCES}

1. Alvar J, Vélez ID, Bern C, Herrero M, Desjeux P, Cano J, et al. Leishmaniasis worldwide and global estimates of its incidence. PLoS One. 2012;7(5):e35671.

2. Conti RV, Lane VFM, Montebello L, Pinto Junior VL. Visceral leishmaniasis epidemiologic evolution in timeframes, based on demographic changes and scientific achievements in Brazil. J Vector Borne Dis. 2016;53(2):99-104.

3. Gontijo CMF, Melo MN. Leishmaniose visceral no Brasil: quadro atual, desfios e perspectivas. Rev Bras Epidemiol. 2004;7(3):338-49.

4. Torres FD. Situação atual da epidemiologia da leishmaniose visceral em Pernambuco. Rev Saude Publica. 2006;40(3):537-41.

5. Dantas-Torres F, Brandão-Filho SP. Expansão geográfica da leishmaniose visceral no Estado de Pernambuco. Rev Soc Bras Med Trop. 2006;39(4):352-6. 
6. Ministério da Saúde (MS). Manual de vigilância e controle da leishmaniose visceral. Manual de Vigilância e Controle da Leishmaniose Visceral. Brasília: MS; 2014. 120p.

7. Instituto Brasileiro de Geografia e Estatística (IBGE). Censo Demográfico 2010. Rio de Janeiro: IBGE; 2010. 199p. Disponível em: www.ibge.gov.br.

8. Kim HJ, Fay MP, Feuer EJ, Midthune DN. Permutation tests for joinpoint regression with applications to cancer rates. Stat Med. 2000;19(3):335-51

9. Araujo AC, Gonçalves NNVM, Dantas-Torres F, Ferreira F, Horta MC. Visceral leishmaniasis in Petrolina, state of Pernambuco, Brazil, 2007-2013. Rev Inst Med Trop Sao Paulo. 2016;58(1):2-5.

10. Ministério da Saúde (MS). Departamento de Informação e Informática do SUS. DATASUS. Informações de Saúde: Epidemiológicas e Morbidades. Brasília: MS; 2006. Disponível em: http://tabnet.datasus.gov.br.

11. Barbosa DS, Belo VS, Rangel MES, Werneck GL. Spatial analysis for identification of priority areas for surveillance and control in a visceral leishmaniasis endemic area in Brazil. Acta Trop. 2014;131:56-62.

12. Margonari C, Freitas CR, Ribeiro RC, Moura ACM, Timbó M, Gripp AH, et al. Epidemiology of visceral leishmaniasis through spatial analysis, in Belo Horizonte municipality, state of Minas Gerais, Brazil. Mem Inst Oswaldo Cruz. 2006;101(1):31-8.

13. Cavalcante IJM, Vale MR. Aspectos epidemiológicos da leishmaniose visceral (calazar) no Ceará no período de 2007 a 2011. Rev Bras Epidemiol. 2014;17(4):911-24.

14. Brandão E, Romero S, da Silva MAL, Santos FLN. Neglected tropical diseases in Brazilian children and adolescents: data analysis from 2009 to 2013. Infect Dis Poverty. 2017;6(1):154.

15. Chappuis F, Sundar S, Hailu A, Ghalib H, Rijal S, Peeling RW, et al. Visceral leishmaniasis: what are the needs for diagnosis, treatment and control? Nat Rev Microbiol. 2007;5(11):873-82.

16. Simon AK, Hollander GA, McMichael A. Evolution of the immune system in humans from infancy to old age. Proc Biol Sci. 2015;282(1821):20143085.
17. Oliveira CDL, Morais MHF, Machado-Coelho GLL. Visceral leishmaniasis in large Brazilian cities: challenges for control. Cad Saude Publica. 2008; 24(12):2953-8.

18. Brazuna JC, Silva EA, Brazuna JM, Domingos IH, Chaves N, Honer MR, et al. Profile and geographic distribution of reported cases of visceral leishmaniasis in Campo Grande, State of Mato Grosso do Sul, Brazil, from 2002 to 2009. Rev Soc Bras Med Trop. 2012;45(5):601-6.

19. Druzian AF, de Souza AS, de Campos DN, Croda J, Higa Jr MG, Dorval ME, et al. Risk factors for death from visceral leishmaniasis in an urban area of Brazil. PLoS Negl Trop Dis. 2015;9(8):e0003982.

20. Oliveira AL, Paniago AM, Dorval ME, Oshiro ET, Leal CR, Sanches $\mathrm{M}$, et al. Emergent outbreak of visceral leishmaniasis in Mato Grosso do Sul State. Rev Soc Bras Med Trop. 2006;39(5):446-50.

21. Oliveira JM, Fernandes AC, Dorval ME, Alves TP, Fernandes TD, Oshiro ET, et al. Mortality due to visceral leishmaniasis: clinical and laboratory characteristics. Rev Soc Bras Med Trop. 2010;43(2):188-93.

22. Góes MAO, de Melo CM, Jeraldo VLS. Time series of visceral leishmaniasis in Aracaju, state of Sergipe, Brazil (1999 to 2008): human and canine aspects. Rev Bras Epidemiol. 2012;15(2):298-307.

23. Furlan M. Visceral leishmaniasis epidemic in Campo Grande, State of Mato Grosso do Sul, Brazil, from 2002 to 2006. Epidemiol Serv Saude. 2010;19(1):16-25.

24. Souza SPO, Mascarenhas MDM, Silva MCB, Almeida RAM. Conhecimento sobre doenças e agravos de notificação compulsória entre profissionais da Estratégia de Saúde da Família no Município de Teresina, Estado do Piauí, Brasil-2010. Epidemiol Serv Saude. 2012;21(3):465-74.

25. Henn GAL, Ramos Júnior AN, Colares JKB, Mendes LP, Silveira $\mathrm{JGC}$, Lima AAF, et al. Is visceral leishmaniasis the same in HIVcoinfected adults? Braz J Infect Dis. 2018;22(2):92-8.

26. Akuffo H, Costa C, van Griensven J, Burza S, Moreno J, Herrero M. New insights into leishmaniasis in the immunosuppressed. PLoS Negl Trop Dis. 2018;12(5):e0006375.

27. Ahluwalia IB, Bern C, Costa C, Akter T, Chowdhury R, Ali M, et al. Visceral leishmaniasis: consequences of a neglected disease in a Bangladeshi community. Am J Trop Med Hyg. 2003;69(6):624-8. 